Farklı teknikler

kullanılarak fiberle

güçlendirilen kompozit

rezinlerin makaslama

bağlanma dayanımının

değerlendirilmesi

\section{The evaluation of shear bond strength of resin composite with different reinforcement techniques}

\section{Dr. Öğr. Üyesi Burcu Oğlakçı}

Bezmialem Vakıf Üniversitesi, Diş Hekimliği Fakültesi, Restoratif Diş Tedavisi AD, İstanbul

Orcid ID: 0000-0002-6587-5997

\section{Doç. Dr. Duygu Tuncer}

Özel Klinik, Mustafa Kemal mah.2129 sok.

1/3 Çankaya, Ankara

Orcid ID: 0000-0003-1623-8892

Uzm. Dt. Derya Merve Halaçoğlu

Yeditepe Üniversitesi, Diş Hekimliği Fakültesi,

Restoratif Diş Tedavisi AD, ìstanbul

Orcid ID: 0000-0003-2569-6887

Prof. Dr. Neslihan Arhun

Başkent Üniversitesi Diş Hekimliği Fakültesi,

Restoratif Diş Tedavisi AD, Ankara

Orcid ID: 0000-0001-7752-5241

Geliş tarihi: 11 Ağustos 2020

Kabul tarihi: 30 Ekim 2020

doi: 10.5505/yeditepe.2021.59489

\section{Yazışma adresi:}

Dr. Öğr. Üyesi Burcu Oğlakçı

Bezmialem Vakıf Üniversitesi Diş Hekimliği Fakültesi,

Restoratif Diş Tedavisi AD, Istanbul

Tel: +90 21245318 50- 5232288

Fax No: +90 2125232288

E-posta: burcu923@hotmail.com
ÖZET

Amaç: Bu çalışmanın amacı, fiberle güçlendirilen kompozit rezinlerin dentine olan makaslama bağlanma dayanımını değerlendirmektir.

Gereç ve Yöntem: 30 adet anonimize sağlam insan molar dişi kullanılmıştır. Dişlerin bukkal ve lingual yüzeyleri, düzgün bir dentin yüzeyi elde etmek için 120-ve 600-gritlik silikon karbid kağıtlarla standart smear tabakası elde etmek için su soğutması altında aşındırımıştır. Ardından, fosforik asit ve adeziv sistem uygulanmıştır. Örnekler, kullanılan fiberin ve kompozit rezinin tipine göre rastgele 5 gruba ayrımıştır $(n=12)$. Grup FZ+PF: mikrohibrit kompozit rezin+polietilen fiber; Grup FZ: mikrohibrit kompozit; Grup EP: kısa fiberle güçlendirilen kompozit; Grup SR+PF: akışkan bulk fill kompozit+polietilen fiber; Grup SR: akışkan bulk fill kompozit. Kompozit rezinler, $3 \mathrm{~mm}$ çap ve $4 \mathrm{~mm}$ yükseklikte silindir şekilde silikon kalıplar kullanılarak bağlanmıştır. Örnekler, 24 saat distile suda bekletilmiş ve ardından $1 \mathrm{~mm} / \mathrm{dk}$ piston başlığı hızında universal test cihazı kullanılarak makaslama bağlanma dayanım testi uygulanmıştır. Kırık yüzeylerin başarısızlık analizi, 15x büyütmede stereomikroskopla incelenmiştir. Veriler, tek yönlü varyans analizi ve Tukey testi kullanılarak değerlendirilmiştir $(p<0,05)$.

Bulgular: Grup SR (akışkan bulk fill kompozit), Grup SR+PF (akışkan bulk fill kompozit+polietilen fiber)'e kıyasla istatistiksel olarak daha yüksek makaslama bağlanma dayanımı göstermiştir $(p<0,05)$. Diğer gruplar arasında istatistiksel olarak makaslama bağlanma dayanımı açısından fark görülmemiştir(p>0,05). Grup FZ (mikrohibrit kompozit), Grup EP (kısa fiberle güçlendirilen kompozit) ve Grup SR (akışkan bulk fill kompozit) karma tip başarısızlık gösterirken; Grup FZ+PF (mikrohibrit kompozit+polietilen fiber) ve Grup SR+PF (akışkan bulk fill kompozit+ polietilen fiber) adeziv tip başarısızık göstermektedir.

Sonuçlar: Akışkan bulk fill kompozit rezinin makaslama bağlanma dayanım değerleri, polietilen fiberle güçlendirilen akışkan bulk fill kompozitlere kıyasla daha yüksektir.

Anahtar kelimeler: Dentin, fiber, kompozit rezin, makaslama bağlanma dayanımı.

\section{ABSTRACT}

Aim: Aim of this study was to evaluate the effect of different fiber-reinforced resin composites on the shear bond strength to dentine.

Materials and Method: 30 anonymized sound human molar teeth's teeth were used. Buccal and lingual surfaces were ground with 120-and 600-grit silicon carbide paper to obtain standard smear layers on dentine under water cooling. Then, phosphoric acid and adhesive system were applied. Specimens were randomly divided into 5 groups according to the type of fiber and resin composites used ( $n=12)$ : Group FZ+PF: microhybrid resin composite+polyethylene fiber; Group FZ: microhybrid composite; Group EP: short fiber-reinforced composite; Group SR+PF: flowable bulk-fill composite+polyethylene fiber; Group SR: flowable bulk-fill composite. Resin 
composites were bonded using cylinder-shaped silicone mold (diameter: $3 \mathrm{~mm}$, height: $4 \mathrm{~mm}$ ). The specimens were stored in distilled water for $24 \mathrm{~h}$ and subjected to shear bond strength test at a crosshead speed of $1 \mathrm{~mm} /$ min using universal testing machine. Debonded surfaces were observed with a steremicroscope under 15x magnification to determine mode of failure. Data were statistically analyzed with one-way variance analysis and Tukey test $(\mathrm{p}<0.05)$.

Results: Group SR (flowable bulk-fill composite) showed statistically higher shear bond strength than Group SR+PF (flowable bulk-fill composite+polyethylene fiber) $(p<0,05)$. There were no significant differences in shear bond strength among other groups $(p>0,05)$. Group FZ (microhybrid composite), Group EP (short fiber-reinforced composite) and Group SR (flowable bulk-fill composite) showed predominantly mixed failures while Group FZ+PF(microhybrid resin composite+polyethylene fiber) and Group SR+PF (flowable bulk-fill composite+ polyethylene fiber) showed adhesive failures patterns.

Conclusions: Flowable bulk-fill composites showed higher shear bond strength than the ones reinforced with polyethylene fiber.

Key words: Dentine, fiber, composite resin, shear bond strength.

\section{GíRiş}

Operatif Dişhekimliği Akademisi Avrupa Bölümü (AODES), kompozit rezinleri posterior dişlerde uygulanan direkt minimal girişimlerde tercih edilmesi gereken restoratif materyal olarak kabul ederken, bu materyallerin yapısal özelliklerinin hala yetersiz olduğunu bildirmektedir.' Kompozit rezin restorasyonların ömrü, restorasyon boyutu ile ters bir orantıya sahiptir. Özellikle geniş restorasyonların kırılmaya bağlı başarısızlığa uğraması daha sıklıkla görülmektedir. ${ }^{2}$ Bu nedenle, adeziv diş hekimliğindeki gelişmeler ile beraber, fiberle güçlendirilen kompozit rezinlerin kullanımı popüler hale gelmiştir. ${ }^{3}$ Fiberle güçlendirme, mevcut geniş restorasyonları ve kalan diş dokusunu okluzal kuvvetlere karşı daha güçlü hale getirmek amacıyla kullanılmaktadır. ${ }^{4}$ Diş hekimliği pratiğinde ayrıca sabit parsiyel protez yapımında, ortodontik retainer olarak, pedodontide yer tutucu olarak, periodontal ve travma splinti olarak da kullanılabilmektedir. ${ }^{5,6}$ Bu materyaller, ağız içerinde uygun bükülme dayanımları ve elastik modülleri sayesinde başarı ile kullanılmaktadır.?

Fiberle güçlendirilen kompozit rezinler, polimer matriks ile fiber yapının bir bütün oluşturması sonucu meydana gelmektedir. Matriks yapı içerisinde oluşan stresler, fiberlere iletilmekte ve böylece restorasyonda veya dişte meydana gelebilecek kırık gelişiminin önüne geçilebilmektedir. ${ }^{8} \mathrm{Li}-$ teratürde, fiberle güçlendirilen kompozit rezinlerin devamIı veya devamlı olmayan fiber yapılar içerdiği belirtilmektedir. ${ }^{9}$ Diş hekimliği uygulamalarında farklı yapıda (karbon, kuartz, aramis, polietilen, cam) fiber materyaller kullanımaktadır. Bunun yanında, bu materyallerin fiber yapılarının dizilimi (tek yönlü ve çok yönlü) de farklıık göstermektedir. Tek yönlü fiberler, tek yönde mekanik özellikler sağladığı için kompozit rezinleri tek yönde güçlendirmiş olurlar. ${ }^{10}$ Bu nedenle, kuvvetin yönünün bilindiği durumlarda kullanılmaları gerekmektedir. Ribbond (Ribbond Inc.) ise çok yönlü çaprazlama kilitli ilmek tarzında leno örgüden oluşan polietilen fiber materyallerdir. ${ }^{3}$ Bu materyaller, kompozit rezinlere her yönden destek sağlamaktadır. ${ }^{11}$ Biyouyumludur, translusenttir ve önceden doyurulma işlemi uygulanmamıştır. ${ }^{22}$ Bunlar dışında, devamlı olmayan kısa fiberlerle güçlendirilen kompozit rezinler de (Ever $X$ Posterior, GC Corp.) piyasaya sürülmüştür. ${ }^{13}$ Bu materyal, rezin matriks ile beraber devamlı olmayan $\mathrm{E}$ (elektriksel) cam fiberlerin ve inorganik doldurucuların kombinasyonu şeklinde bir yapıya sahiptir. Rezin matriks yapısı; çapraz bağlanmış monomerlerden, Bis-GMA ve TEGDMA monomerlerinden oluşmaktadır. Bu kombinasyon, polimerizasyon esnasında yarı birbiri içine geçen polimer ağa neden olmakta; bu da materyale iyi bir bağlanma ve kırılma tokluğu sağlamaktadır. ${ }^{14}$

Fiberler, farklı konfigürasyona ve oryantasyona sahip olmaları nedeniyle farklı klinik uygulamalarda kullanabilmektedir. ${ }^{11}$ Fiberlerin bir kısmı üretim aşamasında, bir kısmı ise rezin içerikli bir ajanla ile uygulama esnasında (polietilen fiber) doyurulmaktadır. Fiberle güçlendirilen kompozit rezinlerin mekanik özellikleri; fiberlerin tipinden, yoğunluğundan, diziliminden, doyurulma şeklinden, matriks yapının içeriğinden veya fiberlerin matrikse bağlanması etkilenmektedir. ${ }^{12,15}$

Juloski ve ark., ${ }^{16}$ fiberle güçlendirilen akışkan kompozit rezinlerin mineye olan makaslama bağlanma dayanımlarının fiber içermeyen akışkan kompozit rezinlerle benzer olduğunu belirtmiştir. Öte yandan, literatürde, fiberle güçlendirilen güncel kompozit rezinlerin farklı diş dokularına adezyonuna ilişkin kısıtlı sayıda çalışma bulunmaktadır. Bu nedenle, bu çalışmanın amacı, fiberle güçlendirilen kompozit rezinlerin dentine olan makaslama bağlanma dayanımını incelemektir. Bu çalışmanın test edilen hipotezi, fiberle güçlendirilen kompozit rezinlerin dentine olan makaslama bağlanma dayanımı arasında fark yoktur şeklindedir.

\section{GEREÇ VE YÖNTEM}

Örnek sayısı, literatürdeki makaslama bağlanma dayanımına ilişkin önceki çalışmalar baz alınarak hesaplanmıştır. $16,17 \% 90$ güçte ve \%5 tip 1 hata oranında orta etki boyutu ( $d=0.50)$ elde etmek için her gruba 12 adet örneğin gerekli olduğu belirlenmiştir. Bu in vitro çalışmada kullanılan restoratif materyaller Tablo 1'de belirtilmiştir. 
Tablo 1. Çalışmada kullanılan restoratif materyaller.

\begin{tabular}{|c|c|c|}
\hline Materyalin ismi & Uretici Firma & Materyalin içeriği \\
\hline Heliobond & \begin{tabular}{|l} 
IVoclar Vivadent (Schaan, \\
Liechtenstein)
\end{tabular} & BIS-GMA ( ağrrlıkça \%60), Trietilen glikol dimetakrilat (ağrrlıkça \%40) \\
\hline $\begin{array}{l}\begin{array}{l}\text { Filltek 7250 } \\
\text { (A2 renk) }\end{array} \\
\end{array}$ & $\begin{array}{l}\text { 3M ESPE } \\
\text { (St Paul MN, ABD) }\end{array}$ & 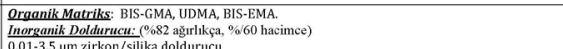 \\
\hline $\begin{array}{l}\text { SDR } \\
\text { (A2 renk) }\end{array}$ & $\begin{array}{l}\text { Dentsply Sirona (York, } \\
\text { ABD) }\end{array}$ & 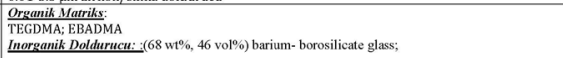 \\
\hline \begin{tabular}{|l}
$\begin{array}{l}\text { EverX Posterior } \\
\text { (Transparan) }\end{array}$ \\
\end{tabular} & $\begin{array}{l}\begin{array}{l}\text { GC, Tokyo, } \\
\text { Japonya }\end{array} \\
\end{array}$ & 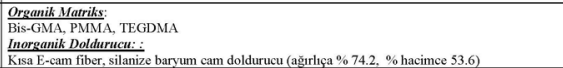 \\
\hline Ribbond & $\begin{array}{l}\text { Ribbond Inc, (Seattle, } \\
\mathrm{WA}_{\mathrm{A}}, \mathrm{BDD} \text { ) }\end{array}$ & Ultra yikssek molekiler ağrrliklı polietilen, Homopolimer H-(CH2-CH2)n-H \\
\hline \begin{tabular}{|l|}
$\begin{array}{l}\text { Adper Single } \\
\text { Bond 2 }\end{array}$ \\
\end{tabular} & $\begin{array}{l}\text { 3M ESPE } \\
\text { (St Paul MN, ABD) }\end{array}$ & 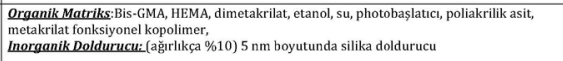 \\
\hline
\end{tabular}

Bu çalışmada, toplam 30 adet ortodontik nedenlerle çekilmiş, anonimize sağlam insan molar dişi kullanıımışıır. Çürüklü, restorasyonlu ya da gözlenebilen defektli dişler çalışmaya dahil edilmemiştir. Diş kökleri servikal üçte birlik bölümleri dışarda kalacak şekilde soğuk akril (Meliodent, Heraeus Kulzer, Almanya) içine gömülmüştür. Dişlerin bukkal ve lingual yüzeyleri, 120 gritlik silikon karbid kağıtlar kullanılarak su soğutması altında aşındırılarak dentin yüzeyleri açığa çıkartılmıştır. Ardından, standart bir smear tabakası oluşturmak için 600 gritlik silikon karbid kağıtlarla su soğutması altında aşındırma işlemi tamamlanmıştır. Açığa çıkan dentin yüzeyleri, 15 sn boyunca \%37'lik fosforik asit ile (Scotchbond Universal Etchant, 3M ESPE, St. Paul MN, ABD) pürüzlendirilmiştir, 10 sn boyunca yıkanmış ve hafif nemli kalacak şekilde pamukla kurutulmuştur. Ardından, Adper Single Bond 2 adeziv sistemi (3M ESPE, St.Paul MN, ABD), üreticinin talimatları doğrultusunda örnek yüzeylerine bond fırçası ile 2 tabaka halinde 15 sn boyunca uygulanmış, hava ile hafifçe inceltilmiş, ışı yayan diyot (LED) ışık cihazı (Woodpecker, Tip B, ışık cihazı, Çin) kullanılarak 1000 mW/cm2 çıkış gücünde 10 sn boyunca polimerize edilmiştir. Örnekler, farklı fiberle güçlendirme tekniklerine ve kompozit rezinlere göre rastgele 5 gruba ayrılmıştır ( $n=12)$.

Grup FZ+PF: Mikrohibrit kompozit rezin (Filtek Z250, 3M ESPE, St.Paul MN, ABD) + doldurucu içermeyen adeziv sistem (Heliobond, Ivoclar Vivadent, Schaan, Liechtenstein) ile ıslatılmış polietilen fiber (Ribbond THM, Ribbond Inc., Seattle, WA, ABD).

Grup FZ: Mikrohibrit kompozit rezin (Filtek Z250, 3M ESPE, St.Paul MN, ABD).

Grup EP: Kısa fiberle güçlendirilen kompozit rezin (EverX Posterior, GC Corp., Tokyo, Japonya).

Grup SR+PF: Akışkan bulk fill kompozit rezin (SDR, Dentsply Sirona, York, ABD) + doldurucu içermeyen adeziv sistem (Heliobond, Ivoclar Vivadent, Schaan, Liechtenstein) ile ıslatılmış polietilen fiber (Ribbond THM, Ribbond Inc., Seattle, WA, ABD).

Grup SR: Akışkan bulk fill kompozit rezin (SDR, Dentsply Sirona, York, ABD).

Grup FZ+PF ve Grup SR+PF için, öncelikle 1 mm kalınlığında akışkan kompozit rezin, silikon kalıplar içerisine yerleştirilmiştir. Ardından uygun boyutta hazırlanmış polietilen fiber, kompozit rezin tabakasının üzerine dentine ulaşıncaya kadar gömülmüştür. Üreticinin talimatları doğrultusunda LED ışık cihazı ile polimerize edilmiştir. Tüm gruplarda, kompozit rezinler, $3 \mathrm{~mm}$ çap ve $4 \mathrm{~mm}$ yükseklikte silindir şekilde silikon kalıplar kullanılarak örnek yüzeylerine bağlanmış ve üreticinin talimatları doğrultusunda LED ışık cihazı kullanılarak polimerize edilmiştir. Örnekler, distile suda $37 \mathrm{C}^{0}$ 'de 24 saat boyunca bekletilmiştir. Ardından, termal siklus cihazında (SD Mechatronik Termocycler THE-1000, Almanya) 5 C0 ve 55 Co'de (batırılma süresi=25 sn, transfer süresi=10 sn) 5000 döngüye tabi tutularak yaşlandırıımıştır. Universal bir test cihazı (Lloyd Lrx, Lyod Instrument, ABD) kullanılarak $1 \mathrm{~mm} / \mathrm{dk}$ piston başlığı hızında keski şeklinde bir uç kullanılarak diş-restorasyon ara yüzeylerinin makaslama bağlanma dayanımları belirlenmiştir. Kırılma esnasına elde edilen değerler Newton (N) cinsinden kaydedilmiştir. Makaslama bağlanma dayanım değerleri, bağlanma alanlarına $(A)$ göre aşağıdaki formül kullanılarak Megapaskal (MPa) cinsinden hesaplanmıştır:

$\mathrm{MPa}=\mathrm{N} / \mathrm{A}$

Tüm örneklerin kırılma yüzeylerinin başarısızlık tipleri, 15 kez büyütme altında stereomikroskop (Leica MZ 21, Leica Microsystems, Almanya) kullanılarak adeziv, koheziv ve karma başarısızlık olarak değerlendirilmiştir. Başarısızlık diş-restorasyon ara yüzeyinde meydana geldiyse, adeziv; kompozit veya dentin içinde oluştuysa koheziv; ara yüzey ve kompozit birlikte etkilendiyse, karma başarısızlık tipi olarak belirlenmiştir.

Elde edilen veriler, Windows için IBM Statistical Package for Social Sciences 22.0 software (SPSS Inc., Chicago, IL, USA) programı kullanılarak analiz edilmiştir. Tüm örneklerin makaslama bağlanma dayanımı değerlerinin varyansların normalliği Shapiro-Wilk testi ve varyansların homojenliği Levene testi ile değerlendirilmiştir. Bu test sonuçlarına göre parametrik test varsayımları sağlandığından test grupları arasındaki farkların istatistiksel analizi tek yönlü varyans analizi (ANOVA) ve ikili karşılaştırmalar ise Tukey testi ile incelenmiştir. Anlamlılık düzeyi $p<0,05$ olarak belirlenmiştir.

\section{BULGULAR}

Tüm test edilen grupların dentine olan ortalama makaslama bağlanma dayanım değerleri ve standart sapmaları (Mpa) Tablo 2'de gösterilmiştir.

Tablo 2. Test edilen tüm grupların ortalama makaslama bağlanma dayanımı ve standart sapma değerleri (Ortalama $\pm S S)(\mathrm{Mpa})(\mathrm{n}=12)$.

\begin{tabular}{|l|l|}
\hline & Makaslama Bağlanma Dayanımı (Mpa) \\
\hline Grup FZ+PF & $11,21 \pm 8,75^{\mathrm{ab}}$ \\
\hline Grup FZ & $17,89 \pm 9,41^{\mathrm{ab}}$ \\
\hline Grup EP & $16,01 \pm 7,78^{\mathrm{ab}}$ \\
\hline Grup SR+PF & $9,31 \pm 6,26^{\mathrm{b}}$ \\
\hline Grup SR & $20,86 \pm 12,25^{\mathrm{a}}$ \\
\hline $\begin{array}{l}\text { Genel karşllaştırmaya ilişkin p } \\
\text { değeri } \\
\text { (Tek yönlü varyans analizi) }\end{array}$ & 0,018 \\
\hline
\end{tabular}

*Farklı harflerle belirtilen üst simgeler, istatistiksel farklılı̆ı belirtmektedir $(p<0,05)$. 
İili karşılaştırma analizini göre Grup SR (akışkan bulk fill kompozit), Grup SR+PF (akışkan bulk fill kompozit+polietilen fiber) kıyasla istatistiksel olarak anlamlı düzeyde daha yüksek makaslama bağlanma dayanım değerleri göstermiştir $(p<0,05)$. Diğer gruplar arasında ise istatistiksel olarak anlamlı bir fark tespit edilmemiştir $(p>0,05)$.

Tüm test edilen grupların başarısızlık tipleri Şekil 1'de gösterilmektedir.

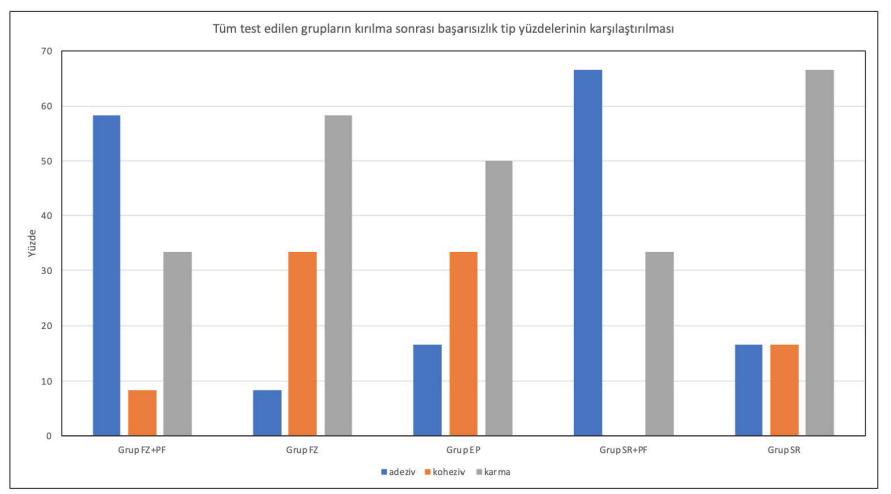

Sekil 1. Tüm test edilen grupların kırılma sonrası bașarısızıı tip yüzdelerinin karşılaştırılması

Grup FZ (mikrohibrit kompozit), Grup EP (kısa fiberle güçlendirilen kompozit) ve Grup SR'de (akışkan bulk fill kompozit) karma tip başarısızlık gözlenirken; Grup FZ+PF (mikrohibrit kompozit+polietilen fiber) ve Grup SR+PF'de (akışkan bulk fill kompozit+polietilen fiber) adeziv tip başarısızlık daha fazla gözlenmektedir.

\section{TARTIŞMA}

Bu çalışmada, fiberle güçlendirilen (polietilen fiber veya kısa fiber) farklı tipte kompozit rezinlerin dentine olan makaslama bağlanma dayanımı araştırımıştır. Fiberle güçlendirilen kompozit rezinlerin dentine olan makaslama bağlanma dayanımı arasında fark yoktur şeklindeki hipotez, akışkan bulk fill kompozit rezinlerin, fiberle güçlendirilen akışkan bulk fill kompozit rezinlere kıyasla daha yüksek makaslama bağlanma dayanımı göstermesi nedeniyle kısmen reddedilmiştir.

Tezvergil ve ark.'ın ${ }^{18}$ akışkan kompozit rezin ile ıslatılmış ve ıslatılmamış fiberle güçlendirilen kompozit rezinlere ilişkin çalışmasında, akışkan kompozit rezin uygulamasının fiber materyallerin makaslama bağlanma dayanımını etkilemediği ortaya konmuştur.Bu nedenle, bu çalışmada, fiber materyaller, üreticinin talimatları doğrultusunda doldurucu içermeyen bir adeziv sistemle (HelioBond) ile ıslatılmış ve ardından dentin yüzeyine uygulanmıştır. ${ }^{19}$ Ayrıca, fiberlerin dentin yüzeylerine uygulanması sırasında HEMA içeren bir adeziv sistem (Adper Single Bond 2) kullanılmıştır. Literatürde, düşük moleküler ağırlığa sahip HEMA monomerinin adezyonu arttırdığı bildirilmiştir. ${ }^{20}$

Termal yaşlandırma, bağlanma dayanım testlerinde ağız ortamını taklit etmek amacıyla en sıkıkla kullanılan yaşlandırma prosedürüdür. Sıcak veya soğuk içeceklerin yarattığı ağız içerisindeki sıcaklık değişimlerini taklit eden suda bekletme protokolünden oluşmaktadır. ${ }^{21}$ SIVI ve ISI değişimleri sonucu bağlanma ara yüzünde termal gerilim yaratılması hedeflenmiştir. Tekrarlanan ısı değişimleri, organik matriksin ve doldurucu partiküllerinin farklı termal genleşme katsayılarına bağlı olarak adeziv ara yüzün devamlı zayıflamasına neden olmaktadır. ${ }^{22}$ Bu nedenle, bu çalışmada kompozit rezin örnekleri, bağlanma sonrasında termal siklus cihazında 5000 döngüye tabi tutularak suni olarak yaşlandırıımıştır. Bu yaşlandırma döngüsü, yaklaşık olarak 6 aylık bir klinik kullanıma karşılık gelmektedir. ${ }^{23}$ Kompozit rezinlerin ve adeziv sistemlerin bağlanma dayanımlarını test etmek için makro ve mikro test yöntemleri kullanılmaktadır. ${ }^{24}$ Makro bağlanma dayanım testleri, göreceli olarak geniş alanların, 3-6 milimetre çapa sahip örneklerin (7-28 mm2) incelenmesinde tercih edilmekte, makaslama ve gerilim testlerinden oluşmaktadır. ${ }^{25} \mathrm{An}$ cak, bağlanma ara yüzeyindeki stresin homojen dağılım göstermemesi nedeniyle bağlanma dayanımının ortalama sayısal değerini tam olarak yansıtamayabilmektedir. ${ }^{26}$ Bu nedenle, daha küçük alana sahip (1 mm2'den daha küçük) örneklerin incelemesinde mikro bağlanma dayanım testleri kullanılmakta ve mikro makaslama ve mikro gerilim testlerini içermektedir. ${ }^{27}$ Ancak, mikro bağlanma testlerindeki artan popülariteye rağmen, bu test yöntemlerinin de bazı dezavantajları mevcuttur: ufak boyuttaki örneklerin deney prosedürünün teknik hassasiyet gerektirmesi, uygulamasının zor olması ve örneklerin dehidratasyon riskidir. ${ }^{28} \mathrm{Bu}$ nedenle, in vitro çalışmalarda makaslama bağlanma dayanım testi, basit ve güvenilir bir yöntem olması nedeniyle restoratif materyallerin bağlanma dayanımlarını değerlendirmek amacıyla sıklıkla tercih edilmektedir. ${ }^{29}$ Çiğneme esnasında meydana gelen kuvvetleri taklit ederek materyalin klinik başarısı hakkında fikir verebilmektedir. ${ }^{30}$ Bu nedenle, bu çalışmada, elde edilen örneklerin bağlanma dayanımları makaslama bağlanma testi kullanılarak değerlendirilmiştir.

Bu çalışmanın sonuçlarına göre, akışkan bulk fill kompozit rezinin dentine olan makaslama bağlanma dayanımı, fiberle güçlendirilen akışkan bulk fill kompozit rezine kıyasla istatistiksel olarak daha yüksek bulunmuştur. Bu bulgu, fiberlerin bağlanma dayanımını arttırmadığını ve hatta azaltabildiğini bildiren önceki çalışma sonuçları ile uyumludur. ${ }^{17}$ Ayrıca, fiberle güçlendirilen mikrohibrit kompozit rezinlerin makaslama bağlanma dayanımları, geleneksel kompozit rezinlere benzer bulunmuştur. Bu bulgu, fiberle güçlendirilen geleneksel kompozit rezinlerin dentine olan makaslama bağlanma dayanımlarının geleneksel kompozitler ile benzer olduğunu belirten daha önceki çalışmaların sonuçlarını destekler niteliktedir., ${ }^{17,31}$ Fiber kullanımının, geleneksel kompozitlerin makaslama bağlanma dayanımını arttırmasa da, restorasyonda çatlak ilerlemesini önlediği ve kütlesel kırık riskini azalttığı bildirilmiştir. ${ }^{32}$

Kısa fiberle güçlendirilen kompozit rezinlerin içeriğinde yer alan protruding yapıya sahip kısa fiberlerin dentin 
dokusu ile mikromekanik kilitlenme sağlaması nedeniyle Grup EP'da alan örneklerde yüksek makaslama bağlanma dayanım değerleri elde edildiği düşünülmektedir. Kısa fiberle güçlendirilen kompozit rezinler ile akışkan bulk fill kompozitler ile benzer makaslama bağlanma dayanımları elde edilmiştir. Bu bulgu, kısa fiberle güçlendirilen kompozitlerin, akışkan bulk fill kompozit rezinlere göre dentine daha yüksek makaslama bağlanma dayanımı gösterdiğini bildiren Omran ve ark.'nın ${ }^{33}$ çalışması ile ters düşmektedir. Bulgulardaki farklılığın, mevcut çalışmada etch-rinse bir adeziv sistem kullanılması ve Omran ve ark.'nın çalışmasında ise universal adeziv sistemin self-etch modunda uygulanması dolayısıyla olduğu düşünülmektedir.

Bu çalışmada, polietilen fiberle güçlendirilen kompozit rezin gruplarında en sıklıkla rastlanan başarısızlık tipi adeziv başarısızlık olmuştur. Polietilen fiberin dentin dokusuna uygulanması sırasında, akışkan kompozit rezin içerisine yerleştirilmesi gerekmektedir. Ancak bu işlem zordur ve teknik hassasiyet gerektirmektedir. Bazı durumlarda, fiber materyali aradaki akışkan kompozitin varlığı nedeniyle dentin dokusuna tam olarak temas edemeyebilir ve bu nedenle adeziv başarısızlık görülebilir. Bu başarısızlık tipi en yüksek oranda fiberle güçlendirilen akışkan bulk fill kompozit rezin grubunda görülmüştür. Ayrıca, bu bulgu, dentine olan makaslama bağlanma dayanımının restoratif materyalin koheziv dayanımından daha düşük olduğunu ortaya koymaktadır. ${ }^{16}$ Kısa fiberle güçlendirilen kompozit rezin grubunda ve fiberle güçlendirme yapılmamış kompozit rezin gruplarında ise en sıklıkla rastlanan başarısızlık ise karma başarısızlık olmuştur. Bu bulgu, bu restoratif materyallerde elde edilen dentine olan yüksek makaslama bağlanma değerlerini destekler niteliktedir. Bu yüksek bağlanma dayanımları, ara yüzeyde yer alan adeziv ve koheziv dayanımları aşmaktadır. ${ }^{34}$

Bu çalışmanın limitasyonlarına ilişkin olarak, örneklere yaklaşık olarak 6 aylık klinik kullanıma denk gelen termal yaşlandırma işlemi uygulanmıştır. Bu nedenle, ileriki çalışmalar, daha uzun süreli yaşlandırmanın fiberle güçlendirilen kompozit rezinlerin bağlanma dayanımı üzerine etkisi üzerine odaklanmalıdır.

\section{SONUÇLAR}

Bu çalışmanın limitasyonları dahilinde şu sonuçlar elde edilmiştir:

Akışkan bulk fill kompozit rezinin dentine olan makaslama bağlanma dayanım değerleri, polietilen fiberle güçlendirilen akışkan bulk fill kompozit rezinlere kıyasla daha yüksek bulunmuştur.

Kısa fiberle güçlendirilen kompozit rezinler, geleneksel kompozit rezinler ve akışkan bulk fill kompozit rezinler en sıklıkla karma başarısızlık gösterirken; polietilen fiberle güçlendirilen kompozit rezinler adeziv başarısızlık göstermiştir.

Önceden doyurulma işlemi uygulanmamış polietilen fi- berlerin kaviteye uygulanması işlemi teknik hassasiyet gerektirmektedir. Bu nedenle, hazır doyurulmuş fiber sistemlerinin tercih edilmesinin daha iyi olabileceği düşünülmektedir.

\section{KAYNAKLAR}

1- Lynch CD, Opdam NJ, Hickel RA, Brunton P, Gurgan S ve ark. Guidance on posterior resin composites: Academy of Operative Dentistry - European Section. J Dent 2014; 42:377-383.

2- Opdam, NJ, Bronkhorst, EM, Roeters, JM, Loomans, BA. A retrospective clinical study on longevity of posterior composite and amalgam restorations. Dent Mater 2007; 23: $2-8$.

3- Chan DC, Giannini M, De Goes MF. Provisional anterior tooth replacement using nonimpregnated fiber and fiberreinforced composite resin materials: A clinical report. J Prosthet Dent 2006; 95: 344-348.

4- Van Heumen CC, Tanner J, van Dijken JW, Pikaar R, Lassila LV ve ark. Five-year survival of 3-unit fiber-reinforced composite fixed partial dentures in the posterior area. Dent Mater 2010; 26: 954-960.

5- Mazzoleni S, Meschia G, Cortesi R, Bressan E, Tomasi $C$ ve ark. In vitro comparison of the flexibility of different splint systems used in dental traumatology. Dent Traumatol 2010;26:30-36.

6- Meiers JC, Freilich MA. Chairside prefabricated fiber-reinforced resin composite fixed partial dentures. Quintessence Int 2001;32:99-104.

7- Sorensen JA, Martinoff JT. Intracoronal reinforcement and coronal coverage: A study of endodontically treated teeth. J Prosthet Dent 1984;51:780-784.

8- Van Heumen CC, Kreulen CM, Bronkhorst EM, Lesaffre $\mathrm{E}$, Creugers NH. Fiber-reinforced dental composites in beam testing. Dent Mater 2008;24:1435-1443.

9- Goldberg A, Burstone C. The use of continuous fiber reinforcement in dentistry. Dent Mater 1992;8:197-202

10- Butterworth $C$, Ellekwa $A E$, Shortall A. Fibre-reinforced composites in restorative dentistry. Dent Update 2003;30:300-306.

11- Butterworth $C$, Ellekwa $A E$, Shortall A. Fiber reinforced composites in restorative dentistry. Dent Update 2003;30:300-306.

12- Ellakwa $A E$, Shortall $A C$, Marquis PM. Influence of fiber type and wetting agent on the flexural properties of an indirect fiber reinforced composite. J Prosthet Dent 2002;88:485-490.

13- Garoushi S, Vallittu PK, Lassila LVJ. Short glass fiber reinforced restorative composite resin with semi-interpenetrating polymer network matrix. Dent Mater 2007;23:13561362.

14- Garoushi S, Säilynoja E, Vallittu PK, Lassila L. Physical properties and depth of cure of a new short fiber reinforced composite. Dent Mater 2013;29: 835-841. 
15- Ellakwa AE, Shortall AC, Marquis PM. Influence of fiber type and wetting agent on the flexural properties of an indirect fiber reinforced composite. J Prosthet Dent. 2002;88:485-490.

16-Juloski J, Beloica M, Goracci C, Chieffi N, Giovannetti $A$ ve ark. Shear bond strength to enamel and flexural strength of different fiber-reinforced composites. J Adhes Dent 2012;15:123-130.

17- Tezvergil A, Lassila LV, Vallittu PK. The shear bond strength of bidirectional and random-oriented fibre-reinforced composite to tooth structure. J Dent 2005;33:509516.

18- Tezvergil A, Lassila LV, Vallittu PK. Strength of adhesive-bonded fiber- reinforced composites to enamel and dentin substrates. J Adhes Dent 2003;5:301-311.

19- Ribbond, Ribbond Inc., https://ribbond.com/applications-composite-restoration.html\#anchor

20- Lastuma "ki TM, Lassila LVJ, Vallittu PK. The semi-interpenetrating polymer network matrix of fiber-reinforced composite and its effect on the surface adhesive properties. J Mater Sci Mater in Med 2003;14:803-809.

21- Van Meerbeek B, Peumans M, Poitevin A, Mine A, Van Ende $A$ ve ark. Relationship between bond-strength tests and clinical outcomes. Dent Mater 2010;26:e100-121.

22- De Munck J, Van Landuyt $K$, Peumans $M$, et al. A critical review of the dura- bility of adhesion to tooth tissue: meth- ods and results. J Dent Res 2005;84:118-32.

23- Morresi AL, D'Amario $M$, Capogreco $M$, Gatto R, Marzo $G$ ve ark. Thermal cycling for restorative materials: does a standardized protocol exist in laboratory testing? A literature review. J Mech Behav Biomed Mater. 2014;29:295308.

24- Van Meerbeek B, Peumans $M$, Poitevin A. Relationship between bond-strength tests and clinical outcomes. Dent Mater. 26:100-21, 2010.

25- Burke FJT, Hussain A, Nolan L. Methods used in dentine bonding tests: an analysis of 102 investigations on bond strength. Eur J Prosthodont Restor Dent. 2008. 16:158-65.

26-DeHoff PH, Anusavice KJ, Wang Z. Three-dimensional finite element analysis of the shear bond test. Dent Mater. 1995;11:126-31.

27- Beloica M, Goracci C, Carvalho CA, Radovic I, Margvelashvili M, Vulicevic ZR, et al. Microtensile vs microshear bond strength of all-in-one adhesives to unground enamel. J Adhes Dent 2010;12:427-33.

28- Pashley DH, Carvalho RM, Sano $H$, Nakajima M, Yoshiyama M, Shono Y, et al. The microtensile bond test: a review. J Adhesiv Dent. 1999;1:299-309

29- Braga RR, Meira JB, Boaro LC, Xavier TA. Adhesion to tooth structure: a critical review of macro test methods. Dent Mater 2010;26:e38-49.

30- Van Noort R, Noroozi S, Howard IC, Cardew G. A cri- tique of bond strength measurements. J Dent 1989;17: 61-67.

31- Tezvergil A, Lassila LV, Vallittu PK. Strength of adhesive-bonded fiber-reinforced composites to enamel and dentin substrates. J Adhes Dent 2003;5:301-311.

32- Quinn GD. Fractography of ceramics and glasses. Gaithersburg: National Institute of Standards and Technology; 2007.

33- Omran TA, Garoushi S, Abdulmajeed A, Lassila LV, Vallittu PK. Influence of increment thickness on dentin bond strength and light transmission of composite base materials. Clin Oral Investig 2017;21:1717-1724.

34- Sabatini $C$. Effect of a clorhexidine-containing adhesive on dentin bond strength stability. Oper Dent 2013;385. 